\title{
O Serviço Social na Inglaterra: a experiência de um estágio de pesquisa
}

\section{The Social Work in England: the experience of a research internship}

\author{
Bianca Ribeiro de Souza ${ }^{a}$ \\ (1) https://orcid.org/0000-0003-4746-6820 \\ Shirleny Pereira de Souza Oliveira ${ }^{b}$ \\ (D) https://orcid.org/0000-0003-4638-9261
}

Resumo: Este artigo é resultado de estágio de pesquisa no exterior realizado na Universidade de Essex - Inglaterra, nos meses de outubro e novembro do ano de 2019. Objetiva apresentar algumas aproximações sobre o debate do Serviço Social inglês, especialmente no que diz respeito às tendências do Serviço Social Radical e Neoliberal, bem como apontar alguns dados levantados em visitas institucionais e em entrevistas realizadas com assistentes sociais desse país.

Palavras-chave: Inglaterra. Estágio de pesquisa. Serviço Social.

\begin{abstract}
This paper is about a research internship abroad held at the University of Essex - England, for a period of two months, October and November 2019. Its purpose is to present some approaches on British Social Work, especially related to Radical and Neoliberal Social Work, as well as pointing out some data collected during institutional visits and interviews with social workers in this country.
\end{abstract}

Keywords: England. Research Internship. Social Work. 


\section{Introdução}

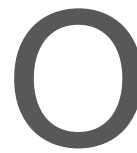

presente artigo é resultado da experiência de um estágio de pesquisa no exterior, realizado pelas autoras nos meses de outubro e novembro de 2019 no Centre for Social Work and Social Justice da Universidade de Essex - Inglaterra, ${ }^{1}$ sob a co-orientação do prof. dr. Vasilios Ioakimidis. ${ }^{2}$ Desse modo, objetiva apresentar algumas aproximações sobre o Serviço Social na Inglaterra, especialmente no que diz respeito às tendências do Serviço Social Radical e Neoliberal, bem como apontar alguns dados levantados em visitas institucionais e em entrevistas realizadas com assistentes sociais desse país.

Inicialmente, é importante contextualizar que a realização do referido estágio se vinculou aos projetos de doutorado das autoras, que tratam, respectivamente, do processamento do trabalho do assistente social nas instituições do sistema de justiça e da autonomia profissional relativa no sistema prisional. Os respectivos projetos têm o Serviço Social como objeto de estudo e, nesta direção, partindo da tese de Netto (2011), de que o Serviço Social deve ser histórica e socialmente compreendido no marco da sociedade burguesa, entendemos como fundamental e de valoroso salto qualitativo para as pesquisas conhecer o debate sobre a

\footnotetext{
A princípio, o estágio de pesquisa seria financiado pela Coordenação de Aperfeiçoamento de Pessoal de Nível Superior (Capes), por meio do Programa de Doutorado-Sanduíche no Exterior (PDSE), em um período de seis meses. Entretanto, devido a mudanças nos critérios de concessão das bolsas, sobretudo no que diz respeito à proficiência em língua estrangeira, em um contexto de cortes sucessivos de recursos no ano de 2019, houve indeferimento dos pleitos no decorrer do processo. Desse modo, as autoras, com o suporte do Programa de Estudos Pós-Graduados em Serviço Social da Pontifícia Universidade Católica de São Paulo - PUC-SP, viabilizaram o estágio por meio de outros recursos, motivo pelo qual foi realizado em período inferior a seis meses.

2 Atualmente o prof. dr. Vasilios é diretor do Centre for Social Work and Social Justice da Universidade de Essex e suas pesquisas direcionam-se para duas áreas específicas: o trabalho profissional em tempos de conflitos e os movimentos de bem-estar de base no contexto de crise financeira e política, com enfoque nos países do Sul europeu e da América Latina. É oportuno ainda destacar que o prof. dr. Vasilios tem estabelecido interlocuções com o Serviço Social brasileiro, com participação em eventos da categoria e intercâmbios acadêmicos.
} 
profissão em outro país, de forma a contribuir para o enriquecimento das determinações que envolvem o objeto em análise.

Neste sentido, tendo em vista que a interlocução do Serviço Social brasileiro no circuito mundial ainda é pouco explorada, conforme sinalizam Yazbek e Iamamoto (2019), e que dentre as tendências teóricas do Serviço Social europeu há uma vertente denominada Radical and Critical Social Work, em uma perspectiva histórico-crítica, avaliamos como oportuna a realização do estágio na citada universidade, uma vez que o prof. dr. Vasilios Ioakimidis é reconhecido como um dos expoentes e estudiosos dessa vertente e dos fundamentos do trabalho profissional.

Assim, objetivou-se conhecer o debate sobre o Serviço Social na Inglaterra, em especial a vertente denominada Serviço Social Crítico e Radical, bem como mapear a inserção de assistentes sociais nos sistemas de justiça e prisional. Tendo em vista tais objetivos, ressalta-se que em decorrência das experiências acadêmicas na Universidade de Essex, o estudo aqui exposto é também resultado de uma pesquisa bibliográfica, contando com importantes referências teóricas do Serviço Social no Reino Unido na cena contemporânea, a exemplo de Ferguson (2019), Herrero (2017) e Ioakimidis (2013 e 2019).

\section{O Serviço Social radical}

Considerando que um dos objetivos do estágio de pesquisa foi conhecer o debate sobre o Serviço Social Crítico e Radical (Radical and Critical Social Work), é fundamental sinalizarmos que no contato com a Universidade observamos uma distinção entre o Radical e o Critical Social Work. Em tempo, o Radical refere-se ao Serviço Social fundamentado na tradição marxista; já o Critical está baseado em outras vertentes teóricas que se propõem a romper com as tradições do Serviço Social conservador, mas que não estão necessariamente ligadas à teoria social de Marx.

Não obstante, é importante reforçarmos que o surgimento das duas vertentes está intrínseca e historicamente relacionado entre si. Conforme 
nos lembra Yazbek e Iamamoto (2019, p. 13), “o Serviço Social crítico contemporâneo, difundido na Europa, Estados Unidos e Oceania, tem sua gênese no Serviço Social Radical de inspiração marxista, da década de 1970, presente na Inglaterra, Canadá, Austrália e EUA".

Por conseguinte, nos limites deste artigo, optamos por estabelecer especificamente algumas aproximações teóricas com o debate do Serviço Social Radical na Inglaterra, haja vista que o referido país foi um dos palcos para a gênese do Serviço Social Radical. Também porque constatamos uma aparente vinculação desse movimento com o projeto ético-político hegemônico do Serviço Social brasileiro.

De antemão, denotamos que o Serviço Social Radical, conforme sinaliza Ioakimidis (2019), consiste numa tradição que emergiu na Europa e, historicamente, influenciou outros continentes, incorporando à profissão a busca pelo compromisso com a justiça social e com as lutas relacionadas a ela, a exemplo das pautas feministas e antirracistas. Nestes termos, Herrero (2017) destaca que o Serviço Social Radical se pauta na defesa e promoção das ações coletivas, a partir de alianças de assistentes sociais com os usuários, estudantes e movimentos sociais; na defesa dos direitos humanos, da justiça social e da democracia; além da busca e denúncia dos problemas e sofrimentos privados, colocando-os na cena pública.

Neste sentido, Ioakimidis (2019), ao falar sobre o desenvolvimento e a evolução do chamado Serviço Social Radical no contexto europeu, sinaliza elementos históricos que desencadearam sua gênese na profissão até suas expressões e atuação nos dias atuais. No entanto, antes de caracterizarmos o Serviço Social Radical, julgamos necessário tecer algumas considerações sobre o surgimento do Serviço Social enquanto profissão na Inglaterra, bem como sobre o contexto social, político e econômico em que este emergiu.

Ioakimidis (2019) destaca a Revolução Industrial na Inglaterra e a Revolução Francesa como marco do surgimento do Serviço Social enquanto profissão, sinalizando as significativas mudanças ocorridas 
na sociedade europeia entre os séculos XVIII e XIX, que resultaram no avanço científico, inovação tecnológica, aumento da produção de riquezas, mudanças nas estruturas econômicas fundadas na economia de mercado, e divisão da sociedade em classes sociais.

Entendemos, com base em Ioakimidis (2019), que tais mudanças resultaram na incorporação de novas teorias políticas e econômicas no campo da racionalidade, substituindo a caridade e o sentimento de coletividade pelo individualismo. Nesse sentido, essas transformações redefiniram as expressões da questão social e o olhar lançado sobre elas. A pobreza, por exemplo, passou a ser vista como uma questão moral num modelo de sociedade que desconectou essa questão das estruturas do sistema e a concebeu como uma expressão de competência individual.

De modo mais específico, ao analisar essas transformações no contexto inglês, percebe-se que as providências tomadas pelo Estado vitoriano ${ }^{3}$ reforçaram esse panorama. Isto é, na medida em que o Estado prosseguiu com seus objetivos de produção de riquezas e aumento das taxas de lucro, sacrificando sua força de trabalho e submetendo-a a péssimas condições, este também passou a empreender medidas para mascarar os efeitos consequentes do capitalismo (Ioakimidis, 2019).

Ioakimidis (2019) aponta como uma expressão de tomada de decisão, em torno da década de 1830, a instituição das Leis dos Pobres (Poor Laws), que garantia um apoio mínimo, redirecionando os indivíduos pobres e ociosos, que já viviam condições desumanas nas ruas, para instituições como as casas de trabalho (workhouses ${ }^{4}$ ), onde eram sujeitados a

3 O termo "Estado vitoriano" é utilizado em referência ao período histórico do reinado da rainha Vitória na Inglaterra ocorrido em meados do século XIX. Entende-se que essa menção ao termo é feita por Ioakimidis (2019) porque foi exatamente nesse período em que a Revolução Industrial se consolidou no país, expressando consigo o auge do desenvolvimento econômico e suas consequências e contradições do ponto de vista social.

4 Melossi e Pavarini (2006) nos lembram que as chamadas casas de correção (house of corrections) e também as casas de trabalho (workhouses), formas precursoras da prisão moderna, foram modelos punitivos implantados em países de crescente desenvolvimento industrial como a Inglaterra, que representavam um projeto estruturado para intervir na situação daqueles que 
circunstâncias de punição e violência. Vale lembrar que naquele período estavam vedadas alternativas de intervenção no enfrentamento à pobreza e ao desemprego, até mesmo a prática da caridade.

Nesse contexto de intervenção estatal frente à questão social surge o Serviço Social na Inglaterra como profissão, mas sua primeira tradição emerge do ideal da caridade cristã. Cabe ressaltar, conforme assinalado pelo referido autor, que com a instituição da Lei dos Pobres e a consequente abolição da caridade nas ruas, essa foi substituída por um perfil mais profissional denominado "caridade científica" que, apesar do nome, era influenciada pelo darwinismo social e a eugenia, portanto, pseudocientífica (Ioakimidis, 2019).

No que concerne às características da prática e do perfil profissional inglês nesse período, Ioakimidis (2019) descreve que as pioneiras eram assistentes sociais do gênero feminino, provenientes da elite de classe média alta. Essas, em sua maioria, vincularam-se inicialmente às chamadas Organizações Sociais de Caridade (Charity Organization Society — COS), seguindo um protocolo de intervenção baseado numa espécie de culpabilização moral do indivíduo por suas condições de vida.

A primeira expressão do Serviço Social Radical na Inglaterra é manifestada, no entanto, anos depois, com a formação dos chamados Movimentos de Assentamento ${ }^{5}$ e a atuação dos profissionais nesse contexto. Com o passar do tempo, alguns grupos de assistentes sociais inseridos nas casas de assentamento, a partir do contato com a realidade dos usuários, passaram a elaborar uma interpretação da realidade mais crítica. Nesse contexto, identifica-se, como exemplo, a aproximação de

não se adaptaram à nova formação social capitalista. Tais instituições tinham como estratégia a utilização de técnicas de imposição do controle da força de trabalho, a noção de disciplina utilizada no ambiente fabril e o apropriamento do lucro decorrente do trabalho forçado.

5 O referido Movimento de Assentamento, efervescente no início do século XX, pode ser entendido como uma expressão da reforma liberal no que tange ao trato da questão social, que tinha como objetivo minimizar a separação entre ricos e pobres, mas que, apesar disso, ainda previa uma prática similar ao das tradicionais Organizações Sociais de Caridade — OSC, pautada no darwinismo social (Ioakimidis, 2019). 
alguns grupos de profissionais aos ideais do socialismo cristão, bem como a constatação de outros grupos mais radicalizados, adeptos das ideias de Marx e Engels (Ioakimidis, 2019).

Constata-se que a partir desse processo de incorporação de um perfil mais radical à profissão no continente europeu, a categoria profissional passou a engajar-se com diversas lutas sociais que estavam ligadas a pautas de vários aspectos da condição humana, inclusive às lutas políticas, a exemplo do combate ao fascismo e nazismo. No entanto, ao final do período pós-Segunda Guerra Mundial, observou-se um movimento gradativo de recuo da vertente radical e, por diversas razões, de reemergência do conservadorismo na profissão de perfil religioso e anticomunista.

Após esse período de retração, Ferguson e Lavalette (2013) assinalam que a vertente radical do Serviço Social renasceu na década de 1970 na Grã-Bretanha, estabelecendo uma relação mais próxima com o movimento sindical e a prática profissional. Já na última década, os autores apontam o Congresso Mundial em Hong Kong, ${ }^{6}$ em 2010, como um marco para a constatação do número significativo de profissionais de diversas nacionalidades, demonstrando interesse de aproximação às ideias críticas e radicais. Não por acaso, Ioakimidis et al. (2013) nos lembram que seria exagero inferir que o Serviço Social transformou-se subitamente em uma profissão radical, pois a incorporação dessa vertente tem sido resultado de um processo histórico, sobretudo de reconhecimento da inserção da profissão num contexto político, resultando em diversas alianças profissionais.

Por fim, cabe-nos destacar que Ioakimidis (2013) sinaliza que o termo "radical" dado a essa vertente do Serviço Social costuma ser alvo de deturpações e críticas por parte dos adeptos da abordagem tradicional da profissão. Sustenta-se o argumento de que aos assistentes sociais deve interessar apenas os aspectos técnicos da prática profissional, descolados da necessidade de reflexões sobre a realidade em que atuam. Em

6 20a Conferência Mundial de Serviço Social, organizada pela Federal Internacional de Trabalhadores Sociais (Fits), pela Associação Internacional de Escolas de Serviço Social (IASSW) e pelo Conselho Internacional de Bem-Estar Social (ICSW). 
outras palavras, significa empreender, ainda nos dias atuais, respostas profissionais baseadas no imediatismo, conduzidas por uma postura de culpabilização moral dos indivíduos, similar à prática das profissionais pioneiras vinculadas às Organizações Sociais de Caridade na gênese da profissão na Inglaterra.

É diante desse panorama que Ioakimidis (2013) reafirma que o que difere substancialmente o Serviço Social Radical da vertente tradicional da profissão é a sua proposta de uma teoria combinada à prática política. Isto é, uma teoria que subsidie a compreensão das causas dos problemas sociais enfrentados pelos usuários da profissão e também pelos próprios assistentes sociais enquanto trabalhadores, ao mesmo tempo em que esteja aliada a uma prática política norteada pelo objetivo da transformação social dessas condições.

\section{O debate contemporâneo sobre o Serviço Social na Inglaterra}

Situados alguns aspectos gerais sobre a gênese do Serviço Social na Inglaterra com enfoque na perspectiva radical, apresentaremos aproximações com o debate contemporâneo da profissão, a partir das contribuições de Ferguson (2019) e Herrero (2017).

Antes de tratarmos especificamente do Serviço Social, é importante situarmos que a Inglaterra é uma das nações que compõem o chamado Reino Unido,7 berço da Revolução Industrial. Historicamente, consolidou-se como uma potência econômica, política e cultural que, apesar de ser considerada desenvolvida, possui um dos maiores índices de desigualdade social no mundo. Para fins de ilustração, Herrero (2017),

O chamado Reino Unido da Grã-Bretanha e Irlanda do Norte consiste em uma união política entre os países Inglaterra, Escócia, País de Gales e Irlanda do Norte, que, juntos, formam um Estado soberano governado por meio de uma monarquia constitucional e um sistema parlamentar. 
com base em dados publicados pela organização Oxfam, ${ }^{8}$ indica que uma em cada cinco pessoas no Reino Unido vive abaixo da linha de pobreza e os $10 \%$ mais ricos da população britânica possuem mais da metade da riqueza total do país. Herrero (2017) aponta que essas desigualdades se expressam na população por meio do sentimento de exclusão política e das oportunidades econômicas, sendo que "as manifestações, iniciadas em Londres em 2011, ou o recente voto a favor do Brexit ${ }^{9}$ podem ser consideradas claras expressões da frustração e do descontentamento social de amplos setores sociais"10 (p. 344).

Nessa seara, Ferguson (2019) analisa que com a crise do capitalismo global em 2008, iniciada com o colapso do banco de investimento americano Lehman Brother, desenvolve-se em muitos países, inclusive na Grã-Bretanha, um processo de austeridade, isto é, cortes de recursos e privatização dos serviços públicos, de forma que a população vulnerável é a mais impactada por esses ajustes. Também destaca que um dos efeitos da crise são os movimentos de resistência popular a essas medidas, sinalizando que no Reino Unido, no final do ano de 2010, houve uma explosão de protestos "contra aumentos nas taxas escolares e cortes nos benefícios estudantis, os quais foram seguidos por meio milhão de fortes manifestações sindicais no início de 2011, acompanhados por uma greve significativa contra investidas do governo às pensões dos trabalhadores [...]" (Ferguson, 2019, p. 435).

No que tange ao Serviço Social nesse contexto, Herrero (2017) problematiza que historicamente a profissão possui protagonismo junto ao governo britânico, na medida em que desde o século XX, especialmente

8 Oxfam (2016). How to Close Great Britain's Great Divide. Disponível em: http://policy-practice. oxfam.org.uk/publications/how-to-close-great-britains-great-divide-the-business-oftackling-inequality-620059. Acesso em: 12 jan. 2020.

9 Brexit consiste na junção das palavras em inglês British (britânica) e exit (saída). O termo é usado para se referir à proposta de saída do Reino Unido do acordo firmado com o bloco econômico da União Europeia (UE), ao qual tem estado vinculado desde a década de 1970.

10 "las revueltas, iniciadas en Londres en 2011, o el reciente voto en favor del Brexit pueden ser consideradas claras expresiones de la frustración y desafección social de amplios sectores sociales". 
com o desenvolvimento e a expansão do Estado de Bem-estar Social e das políticas neoliberais no final dos anos 1980, os assistentes sociais têm sido delegados para dar respostas superficiais a expressões da questão social aclamadas pela opinião pública. Herrero ainda analisa que, apesar do pioneirismo britânico na construção do Serviço Social como profissão científica, de defesa dos direitos humanos e da justiça social, nos últimos anos o país também tem se revelado pioneiro na constituição do chamado Serviço Social neoliberal, o qual se revela como uma ameaça aos valores historicamente construídos pela profissão.

Em linhas gerais, identifica-se que o Serviço Social neoliberal expressa uma categoria profissional fragmentada, situada numa posição de subserviência em todos os âmbitos: da prática e regulamentação da profissão ao contexto da formação. Para explicar esse movimento, Herrero (2017), com base em Harris (2014), destaca que os efeitos do neoliberalismo no Serviço Social inglês perpassam por três processos fundamentais: mercantilização, cultura do consumo e novo gerencialismo.

De acordo com Herrero (2017), a mercantilização se expressa por meio da privatização dos serviços sociais, ou seja, empresas privadas ou o chamado terceiro setor é subcontratado para prestar esses serviços públicos. Já a cultura do consumo sustenta-se na premissa de responsabilização dos usuários dos serviços sociais, os quais passam a ser consumidores de políticas sociais personalizadas. Ferguson (2019, p. 446) elucida que essa personalização significa "fornecer aos indivíduos uma quantia em dinheiro (conhecida como pagamento direto ou orçamento individual/ pessoal) para permitir que eles se assistam".

Por fim, Herrero (2017) destaca que o novo gerencialismo refere-se à transferência dos valores e técnicas próprios do setor privado para o setor público. A respeito disso, Dardot e Laval (2016) sinalizam que uma vez que a lógica do mercado é incorporada pelo Estado, a gestão dos serviços públicos sofre consequências. a exemplo do aumento da centralização burocrática, ênfase nos indicadores de desempenho e estipulação de metas. Com isso, o trabalhador do ramo dos serviços públicos é requerido 
a dar respostas profissionais alinhadas ao modelo gerencial. Por essa razão, Herrero (2017) destaca que esse movimento impacta no processo de construção da identidade profissional dos assistentes sociais, haja vista que os trabalhadores não se identificam mais com os valores da profissão, mas sim com os da organização empregadora.

Em suma, Herrero (2017) situa que, sob a lógica neoliberal, o debate sobre o Serviço Social inglês é marcado por dois extremos: de um lado uma concepção ampla de profissão, fundamentada em uma prática centrada nas relações, nos direitos humanos e na justiça social, em consonância com a visão de Serviço Social da Federação Internacional de Trabalhadores Sociais (Fits); do outro lado do debate encontra-se uma concepção reducionista, marcada por intervenções burocráticas, limitadas e de manejo de riscos.

\section{A experiência do estágio de pesquisa}

Conforme apontado na Introdução, um dos objetivos do estágio de pesquisa foi mapear a inserção de assistentes sociais nos Sistemas de Justiça e Prisional, uma vez que os objetos dos projetos de doutorado das respectivas autoras tratam do trabalho profissional na área sociojurídica (Borgianni, 2013). No entanto, assim que chegamos à Universidade de Essex, observamos distinções nas formas de organização dessas instituições e, consequentemente, de inserção do Serviço Social. Cabe ainda situar que a experiência aqui relatada é bastante localizada, ou seja, trata-se de uma aproximação inicial realizada em um período de dois meses e em uma dada região da Inglaterra, motivo pelo qual nossas análises se restringirão a esse universo específico.

Durante os meses do estágio, as autoras participaram de atividades do curso de graduação em Serviço Social da Universidade ${ }^{11}$, campus de

11 A Universidade possui três campi: Southend Campus, Colchester Campus e East 15 (Loughton) Campus. 
Southend-on-sea, bem como realizaram visitas institucionais e entrevistas com profissionais de Serviço Social. Esse campus situa-se na cidade de Southend-on-sea, localizada no condado de Essex, a aproximadamente 67 quilômetros de Londres, capital da Inglaterra, com uma população de 182.500 habitantes, segundo dados do ano de $2018 .{ }^{12}$

Logo que chegamos à Universidade, expusemos para os professores o interesse em mapear a inserção do Serviço Social nos Sistemas de Justiça e Prisional, e estes apontaram que naquela localidade não havia assistentes sociais diretamente lotados nessas instituições, exceto no serviço denominado Probation, vinculado à Justiça Criminal. Os professores esclareceram que os assistentes sociais estão inseridos no Council, instituição pública local — que pode ser traduzido como uma espécie de câmara municipal —, responsável por representar os interesses da comunidade, por meio da promoção do debate político, da oferta de serviços e da tomada de decisões. Os councils são compostos por mayor (presidente da câmara), leader (líder), cabinet members (membros do gabinete) e council officers (oficiais da câmara), sendo que a cada quatro anos há eleições locais para a escolha desses representantes pela comunidade. No que se refere à prestação de serviços, o Council é responsável pela emissão de documentos, coleta de lixo, cultura e lazer, educação, saúde, moradia, transporte, entre outros.

No Council da cidade de Southend-on-sea - Southend-on-sea Borough Council - há um serviço denominado Children and Family, no qual estão concentrados os assistentes sociais. Esses profissionais desempenham, fundamentalmente, intervenções de cuidado e proteção a crianças e suas famílias, bem como prestam suporte técnico aos juízes do Tribunal de Justiça em questões referentes à adoção e inserção em família acolhedora (adoption and fostering), além de demandas relativas a adolescentes autores de ato infracional (young offender), por meio da emissão de relatórios e pareceres.

12 Dados disponíveis em: https://www.nomisweb.co.uk/reports/lmp/la/1946157203/report. aspx\#tabrespop. Acesso em: 10 jan. 2020. 
Na oportunidade, tivemos contato com assistentes sociais que trabalham no Council e pudemos perceber que, diferentemente da realidade brasileira, na qual há profissionais lotados no Poder Executivo e no Poder Judiciário, por exemplo, em Southend-on-sea as demandas que exigem intervenção do Serviço Social são direcionadas e concentram-se junto aos profissionais lotados no Council, que são responsáveis tanto por intervenções que não estão judicializadas, quanto por aquelas que estão sob o acompanhamento do Tribunal de Justiça. Essa mesma organização também foi identificada em visita institucional realizada à prisão HM Prison Chelmsford, situada na cidade de Chelmsford, no condado de Essex, cuja capacidade é para 700 presos jovens - entre 18 e 21 anos - e adultos, ambos do sexo masculino.

A prisão de Chelmsford é um estabelecimento ${ }^{13}$ local de categoria de longo prazo B, ${ }^{14}$ que foi construído em 1819 e atualmente recebe indivíduos sentenciados, em prisão preventiva ou aguardando julgamento. $O$ regime de funcionamento dessa prisão tem como propósito reduzir as taxas de reincidência e promover o aumento da empregabilidade dos internos, visando seu retorno à sociedade. Com esse intuito, a unidade segue uma política rigorosa de oferta de cursos profissionalizantes - jardinagem, reciclagem, dentre outros - a atividades de educação, como aulas de matemática e inglês para todos os internos e, nesse contexto, conta com a parceria de empresas privadas externas - dentre elas a Sodexo, que abordaremos adiante — para administração dessas atividades, em termos de promoção de serviços e recrutamento de profissionais especializados.

Durante a visita, observamos a ausência de equipe de Serviço Social no interior dessa prisão e fomos informadas que ao serem identificadas

13 Disponível em: http://www.justice.gov.uk/contacts/prison-finder/chelmsford. Acesso em: 15 jan. 2020.

14 As categorias de funcionamento das prisões no Reino Unido são estipuladas com base em dois critérios: a probabilidade de o preso escapar e o seu potencial ofensivo perante os outros presos e os funcionários da prisão. Para entender de que modo estão organizadas estas categorias, sugerimos conferir: https://www.doingtime.co.uk/how-prisons-work/how-do-prisons-actually-work/types-of-prison-and-prisoners/. Acesso em: 15 jan. 2020. 
situações, pelos profissionais da unidade prisional, que requerem a intervenção do Serviço Social - como interlocuções com as famílias dos presos e emissão de relatórios, por exemplo -, os profissionais lotados no Council são acionados para prestar o suporte.

Ao longo dos diálogos com os professores e com os profissionais entrevistados também pudemos observar, conforme já sinalizado, que no âmbito da Justiça Criminal é possível identificar a presença de assistentes sociais no denominado Probation, serviço destinado a pessoas que estão em liberdade condicional. A liberdade condicional é planejada e acompanhada por profissionais que ocupam o cargo de probation officer, cujas atividades destinam-se a atendimentos aos usuários em cumprimento de sentença. Nessas interlocuções apreendemos que o cargo de probation officer pode ser exercido por profissionais formados em diversas áreas, inclusive em Serviço Social. Portanto, se comparado à realidade brasileira, poderíamos inferir aproximações com os chamados cargos genéricos ${ }^{15}$ presentes em muitas instituições públicas, tais como analista social, gestor de programas e projetos, analista de promotoria, entre outros.

No bojo dessa discussão, Herrero (2017) aponta que na lógica gerencialista da administração dos serviços públicos, própria do neoliberalismo e presente no contexto inglês, há uma tendência "pela criação de postos de trabalho que requerem a titulação de Serviço Social, mas recebem um nome alternativo e envolvem tarefas limitadas: como por exemplo, oficial de proteção a crianças ou gestor de atenção social"16 (Herrero, 2017, p. 350). Assim como no debate brasileiro, a autora (2017) problematiza os efeitos desa tendência na identidade profissional, haja vista "A erosão da identificação dos assistentes sociais com a profissão de serviço social e seus valores, uma vez que sob o novo gerenciamento eles são obrigados a

5 Objeto da Resolução n. 572/2010 do Conselho Federal de Serviço Social (CFESS).

16 "por la creación de puestos de trabajo que requieren la titulación de Trabajo Social, pero reciben un nombre alternativo e implican unas tareas limitadas: como por ejemplo, 'oficial de protección de menores' o 'gestor de atención social'”. 
se identificar primeiro com sua organização e seus interesses" ${ }^{\text {17 }}$ (Herrero, 2017, p. 350, grifos da autora).

Outro ponto identificado ao longo das aproximações com os profissionais diz respeito à tendência de terceirização dos serviços públicos, questões problematizadas por autores como Herrero (2017) e Ferguson (2019). Herrero destaca que sob a lógica neoliberal os Estados nacionais passam a criar mercados em setores antes inexistentes, como por exemplo, no caso da Inglaterra, nas indústrias nacionais públicas de transporte, água, energia, assim como em serviços de saúde e sociais. Já Ferguson, em sua análise sobre as implicações da crise de 2008 e o desenvolvimento de um quadro ideológico fundamentado na Big Society, ${ }^{18}$ afirma que esse cenário produziu no Reino Unido a abertura dos serviços públicos "para concorrência de 'qualquer fornecedor qualificado'; a terceirização de serviços, em outras palavras, se tornará o posicionamento padrão" (2019, p. 448).

Essas tendências sinalizadas pelos autores foram identificadas no decorrer do estágio ao entrarmos em contato com o serviço Probation, o qual é prestado diretamente pelo Estado ou por empresas privadas. Em geral, o gerenciamento da liberdade condicional, vinculada a crimes de menor potencial ofensivo, é efetuado por empresas privadas; já as ações relativas a infrações graves estão sob a responsabilidade estatal. O serviço Probation com o qual tivemos contato é de natureza privada, gerenciado pela empresa Sodexo, ${ }^{19}$ a qual também é responsável pela administração da HM Prison Chelmsford.

17 "la erosión de la identificación de los trabajadores sociales con la profesión del Trabajo Social y sus valores, ya que bajo el new management se les exige identificarse en primer lugar con su organización y los intereses de la misma".

18 De acordo com Ferguson (2019, p. 445), a ideia de Big Society foi apresentada pela primeira vez em uma palestra pública ministrada pelo então primeiro-ministro do Reino Unido, David Cameron, em meados de 2009. Em linhas gerais, conforme o autor, a Big Society é uma crítica ao Big State, "uma tentativa de enfraquecer e abalar as esperanças da população ao procurar apoio no Welfare State quando estão doentes, desempregados ou idosos, transferindo a responsabilidade do Estado para o indivíduo".

19 A Sodexo é uma empresa multinacional francesa que possui filiais em 67 países, inclusive Brasil, atuando no ramo alimentício e de gestão de facilidades. Os serviços prestados podem 
A partir das visitas realizadas no Council e na HM Prison Chelmsford, assim como das entrevistas efetuadas com assistentes sociais e outros profissionais, pudemos estabelecer uma primeira aproximação ao modo como o Estado britânico tem respondido às expressões da questão social, tais como o desemprego, a violência, a exposição de crianças e adolescentes a situações de risco, dentre outras. Nessas aproximações, notamos como as particularidades sociais, políticas, econômicas, culturais e geográficas de cada país impactam nas formas como a questão social se expressa na vida da população e nas respectivas formas de intervenção do Estado.

A título de ilustração, tivemos conhecimento, na visita à prisão, que na proximidade do inverno é comum o aumento do número de presos que cometem delitos de baixo potencial ofensivo, cujas penas perduram por período aproximado de três meses. De acordo com os profissionais entrevistados, dado o inverno rigoroso na Inglaterra, esses usuários vislumbram a prisão como um espaço protetivo diante das baixas temperaturas, assim como de acesso à alimentação e acolhida. Outro ponto que nos chamou a atenção, conforme indicado pelos profissionais do Council, foi a ausência de serviços de acolhimento institucional para crianças e adolescentes na Southend-on-sea, mas sim a inserção em famílias acolhedoras, ${ }^{20}$ para fins de promoção de um ambiente familiar, com garantia da atenção individualizada e da convivência comunitária.

Neste sentido, como apontado por Yazbek e Iamamoto (2019) e com base nas aproximações que efetuamos sobre a gênese do Serviço Social

variar em cada país, desde a prestação de serviços de limpeza, seguros, gerenciamento de energias e outros recursos. No Reino Unido, especificamente, dentre os serviços prestados, a Sodexo também atua na administração de algumas prisões, do probation e das chamadas Community Rehabilitation Companies (CRCs) — empresas de reabilitação comunitária. Disponível em: https://uk.sodexo.com/your-industry/justice.html. Acesso em: 15 jan. 2020.

20 No Brasil encontramos uma realidade bastante diversa. De acordo com publicação do Conselho Nacional do Ministério Público (CNMP), referente a dados coletados entre março de 2012 a março de 2013, no país há 2.247 entidades de acolhimento institucional (abrigos e casas-lares) que atendem a 29.321 acolhidos; e 123 serviços de acolhimento familiar, que atendem a 1.019 pessoas. Disponível em: https://www.cnmp.mp.br/portal/images/stories/Noticias/2013/ Arquivos/Relat\%C3\%B3rio_Acolhimento.PDF. Acesso em: 5 abr. 2020. 
na Inglaterra e seu desenvolvimento contemporâneo, observamos que a "matéria" sobre a qual incide o trabalho do assistente social - as expressões da questão social - possui uma mesma origem. Entretanto, os exemplos indicados acima retratam como as particularidades dos países alteram as formas como a questão social se expressa e as respectivas respostas estatais frente à contradição capital e trabalho.

\section{Considerações finais}

Situados os aspectos principais decorrentes do estágio de pesquisa, em interlocução com as referências teóricas trabalhadas, podemos observar que a experiência nos proporcionou, enquanto pesquisadoras acadêmicas, um intercâmbio de conhecimentos entre o Serviço Social brasileiro e o inglês. Conforme sinalizado, a profissão na Inglaterra, apesar de inserida numa realidade e formas de organizações diferentes, em alguns pontos possui similaridades com o debate do Serviço Social brasileiro.

Compreendemos, com base em Yazbek e Iamamoto (2019), que estas similaridades são resultados de desafios comuns, decorrentes do processo de mundialização do Capital. Basta lembrarmos, segundo Raichelis (2018), que os assistentes sociais, entendidos como trabalhadores especializados, sofrem impactos decorrentes das estratégias de controle e gerenciamento do Capital, tais como os processos de rotinização, intensificação e precarização do seu trabalho. Estes processos reverberam na profissão de inúmeras formas, a depender da realidade nacional: a precarização das condições de vida e de trabalho dos profissionais; fragilização da relativa autonomia profissional nas instituições; a descaracterização da identidade profissional; redução de postos de trabalho, dentre outros.

Neste sentido, Yazbek e Iamamoto (2019), ao debaterem sobre o Serviço Social no circuito mundial, destacam que a profissão deve ser situada na chamada "unidade de diversos". Isto é, para as autoras, embora existam diversidades nacionais - tais como as múltiplas formas em que podem se expressar a questão social, as relações entre as classes sociais e as 
políticas públicas adotadas como respostas pelo Estado -, é necessário reconhecer a importância de firmar uma unidade da categoria profissional.

Por essa razão, Yazbek e Iamamoto (2019) atribuem a importância de dar visibilidade às diversidades protagonizadas pelo Serviço Social em diferentes países e romper com o relativo afastamento do Serviço Social brasileiro em relação ao debate mundial. Dentre as iniciativas apontadas com o intuito de construir esse movimento de unidade, destacam a importância de compartilhar "o aperfeiçoamento acadêmico e ético-político da formação e do exercício profissionais” (p. 12), que entendemos que podem também ser fomentados a partir da pesquisa acadêmica em experiências decorrentes da internacionalização dos programas de pós-graduação em Serviço Social.

Tomando como referência a importância em ressignificar um movimento de aproximação com o Serviço Social em outros países, analisamos que a experiência do estágio de pesquisa na Inglaterra foi profícua não apenas para aprofundar as pesquisas de doutorado das autoras, mas também para fortalecer os vínculos da nossa categoria profissional com outros países, promovendo o intercâmbio de ideias, experiências e a construção de novos campos de pesquisa.

\section{Referências}

BORGIANNI, E. Para entender o Serviço Social na área sociojurídica. Serviço Social \& Sociedade, São Paulo, n. 115, 2013. Disponível em: http://www.scielo.br/scielo. php?script=sci_arttext\&pid=S0101-66282013000300002. Acesso em: 23 jan. 2020.

DARDOT, P.; LAVAL, C. A nova razão do mundo: ensaio sobre a sociedade neoliberal. Tradução Mariana Echalar. São Paulo: Boitempo, 2016.

FERGUSON, I. Da modernização à big society: continuidade e mudança no Serviço Social no Reino Unido. In: YAZBEK, M. C.; IAMAMOTO, M. V. Serviço Social na história: América Latina, África e Europa. São Paulo: Cortez, 2019.

FERGUSON, I.; LAVALETTE, M. Critical and Radical Social Work: An Introduction. Critical and Radical Social Work, Bristol, v. 1, n. 1, p. 3-14, abr. 2013. Disponível em: https://doi. org/10.1332/204986013X665938. Acesso em: 18 jan. 2020. 
HARRIS, J. (Against) Neoliberal Social Work. Critical and Radical Social Work, Bristol, v. 2, n. 1, p. 7-22, 2014.

HERRERO, M. I. M. El trabajo social en Inglaterra: el principio y fin de una profesión para la justicia social? Cuadernos de Trabajo Social, Madri, v. 30, n. 2, p. 343-355, 2017. Disponível em: http://dx.doi.org/10.5209/CUTS.54606. Acesso em: 10 jan. 2020.

IOAKIMIDIS, V. A Guide to Radical Social Work. The Guardian, 2013. Disponível em: https:/www.theguardian.com/social-care-network/2016/may/24/radical-social-workquick-guide-change-poverty-inequality. Acesso em: 19 jan. 2020.

IOAKIMIDIS, V. Reflexões sobre a história: desenvolvimento e evolução do Serviço Social radical na Europa. Libertas, Juiz de Fora, v. 19, n. 2, 2019. Disponível em: https://periodicos. ufjf.br/index.php/libertas/article/view/28978/19930. Acesso em: 10 jan. 2020.

IOAKIMIDIS, V. et al. Austerity and social work in Europe: listening to the voices of resistance. Critical and Radical Social Work, Bristol, v. 1, n. 2, p. 253-261, 2013. Disponível em: https://doi.org/10.1332/204986013X673317. Acesso em: 12 jan. 2020.

MELOSSI, D.; PAVARINI, M. Cárcere e fábrica: as origens do sistema penitenciário (séculos XVI-XIX). 2. ed. Rio de Janeiro: Revan/ICC, 2006.

NETTO, J. P. Capitalismo monopolista e Serviço Social. São Paulo: Cortez, 2011.

RAICHELIS, R. Serviço Social: trabalho e profissão na trama do capitalismo contemporâneo. In: RAICHELIS, R.; DAMARES, V.; ALBUQUERQUE, V. (orgs.). A nova morfologia do trabalho no Serviço Social. São Paulo: Cortez, 2018.

YAZBEK, M. C.; IAMAMOTO, M. V. Introdução. In: YAZBEK, M. C.; IAMAMOTO, M. V. Serviço Social na história: América Latina, África e Europa. São Paulo: Cortez, 2019.

\section{Sobre as autoras}

Bianca Ribeiro de Souza - Doutoranda em Serviço Social e Assistente Social. E-mail:biarsouza@hotmail.com

Shirleny Pereira de Souza Oliveira - Doutoranda do Programa de Estudos Pós-Graduados em Serviço Social.

E-mail: oliveirashirleny@gmail.com 